\title{
ARTEFACTOS CULTURALES DE LA PRENSA GREMIAL DOCENTE DE LA PROVINCIA DE RÍO NEGRO (1990-2000)
}

\author{
Susana Ana María Tarantino * \\ ISFD № 12/ Universidad Nacional del Comahue, Argentina \\ suan_tar@hotmail.com \\ Nora Antonia Silva ** \\ Universidad Nacional del Comahue, Argentina \\ norasilva09@hotmail.com \\ Nancy Liliana Salerno *** \\ Universidad Nacional del Comahue, Argentina \\ nancylilianasalerno@hotmail.com
}

Recibido: 2/08/2020 - Aceptado: 11/01/2021

\section{Resumen}

El presente trabajo constituye una aproximación al contenido del discurso de la prensa gremial escrita en relación con el campo educativo, específicamente de un gremio docente provincial, la Unión de Trabajadores de la Educación de Río Negro (UnTER) durante la década del noventa bajo los gobiernos sucesivos de Carlos Saúl Menem (1989-1999). Este período se caracterizó por el recrudecimiento de las medidas neoliberales.

Se busca significar la trama discursiva en el periódico "La escuela en marcha", las "Memorias"; los cuadernos de capacitación y divulgación llamados "La UnTER en la escuela"; y en tres ejemplares anuales de las revistas "Quimán".

El análisis de estos artefactos culturales permite indagar sobre su conceptualización, funciones y relevancia que lograron en un arco temporal que abarcó desde 1993 a 1999. Se intentará dilucidar, por un lado, si se constituyeron en soportes de información, reflexión y formación, para contraargumentar el discurso hegemónico y por el otro, si actuaron como herramientas valiosas de lucha y resistencia, frente al avance de políticas de ajuste y descentralización de la educación pública.

Palabras clave: Prensa gremial - Artefactos culturales - Resistencia y lucha.

\section{CULTURAL ARTIFACTS OF THE TEACHING UNION PRESS IN THE PROVINCE OF RIO NEGRO (1990-2000)}

\footnotetext{
Abstract

The present work constitutes an approach to the content of the speech of the written trade union press in relation to the educational field; specifically of a provincial educational union, the Union of Workers of the Education of Río Negro (UnTER) during the nineties under the Carlos Saúl Menem

*Especialista en Didáctica de las Ciencias Sociales con mención en Educación Ciudadana. Especialista en Jardín Maternal. Profesora en Ciencias de la Educación. Profesora en el Nivel Inicial. Integrante del equipo de investigación del Departamento de Historia de la Educación.

${ }^{* \star}$ Especialista en Didáctica de las Ciencias Sociales con mención en Educación Ciudadana. Profesora en Ciencias de la Educación. Profesora en Enseñanza Primaria.

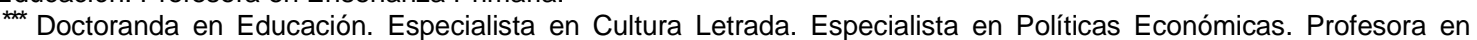
Historia. Asistente de Docencia Regular.
} 
REVISTA DE LA ESCUELA DE CIENCIAS DE LA EDUCACIÓN, AÑO 17, NRO. 16, VOL. 1, ENERO A JUNIO DE 2021. PÁGINAS 51-57. ISSN 2362-3349 (EN LíNEA). ARTEFACTOS CULTURALES DE LA PRENSA GREMIAL DOCENTE DE LA PROVINCIA DE RIO NEGRO (1990-2000). SUSANA ANA MARÍA TARANTINO. NORA ANTONIA SILVA. NANCY LILIANA SALERNO.

successive governments (1989-1999). This period was distinguish due to the increase of neoliberal measures.

The aim of this article is to signify the discursive plot in the newspaper "La Escuela en marcha" "Memorias"; the training and dissemination notebooks called "La UnTER en la escuela"; and in three annual copies of the "Quimán" magazines.

The analysis of these cultural devices allows us to inquire about their conceptualization, functions and relevance that they achieved in a time arc that spanned from 1993 to 1999. An attempt will be made to elucidate, on the one hand, to elucidate if these cultural mechanisms acted as supports for information, reflection and training, to counter - to argue the hegemonic discourse and, on the other hand, if they acted as valuable tools of struggle and resistance, in the presence of the advancement of policies of adjustment and decentralization of public education.

Keywords: Union press - Cultural artifacts - Resistance and struggle.

\section{Introducción}

El campo disciplinar en el que se desarrolla el presente trabajo corresponde a la Historia de la Educación Regional. ${ }^{1}$ Este estudio constituye una aproximación al contenido del discurso de la prensa gremial escrita en relación con el campo educativo, específicamente de un gremio docente provincial, la Unión de Trabajadores de la Educación de Río Negro (UnTER) ${ }^{2}$ durante la década del noventa bajo los dos gobiernos sucesivos de Carlos Saúl Menem (1989-1999).

Este período se caracterizó por el recrudecimiento de las medidas neoliberales en el proceso de crisis del Estado de Bienestar y su influencia en los sindicatos como representantes de los trabajadores. El avance de estas políticas se dinamizó con la destrucción del tejido socio-económico y, por consiguiente, el ajuste estructural cambió las relaciones entre Estado y sociedad, privilegiando la lógica del mercado como el único asignador eficiente de recursos, cuestionándose el papel del Estado en su rol de productor de bienes y servicios y como redistribuidor de la riqueza. De este modo, la política quedó desplazada como lugar de producción del orden social y el Estado pasó a jugar un rol mínimo, subsidiario con medidas generales tales como la descentralización, la privatización y la desregulación que tuvieron su correlato, según lo indican Nosiglia y Marquina (2000) en la dimensión educativa, sumándoseles la desburocratización y la eficientización económica del sistema educativo público, asumiendo "características fundacionales por su integralidad y extensión" (Nosiglia y Marquina, 2020, p. 165).

En este escenario, la conflictividad docente en Río Negro, fue incrementándose en forma progresiva y paralela al proceso de transferencia de los servicios educativos de la Nación correspondientes al Nivel Medio y Superior a la provincia (Ley 24.049/91). Esto implicó agravar la difícil situación económica del territorio y el rechazo a la implementación de la Ley Federal de Educación (Ley 24.195/93) como también al proyecto de ley sobre la profesionalización docente ${ }^{3}$ en términos similares a una flexibilización laboral en el marco de la aplicación de la Ley Superior de Educación (Ley 24.521/97).

Esta sostenida oposición del gremio UnTER fue acompañada por el accionar de todas las asociaciones gremiales nucleadas en la Confederación de Trabajadores de la Educación de la República Argentina -CTERA-.

En esta oportunidad, se centrará el análisis en los distintos artefactos culturales ideados por la prensa gremial escrita indagando sobre su conceptualización, funciones y relevancia que lograron en los noventa, considerándolos herramientas valiosas que reflejan concepciones e intereses que se contraponen con el discurso gubernamental, y, por ende, con las políticas educativas que pretendieron implementar. Asimismo, pretender observar la construcción de poder desde las bases, las vinculaciones estratégicas con otros gremios y las tensiones que surgen en escenarios de confrontación o negociación con el poder político provincial y nacional. El corpus documental analizado consta del periódico "La escuela en marcha", las "Memorias"; los cuadernos de capacitación y divulgación llamados "La UnTER en la escuela”; y, por último, tres ejemplares anuales de las revistas "Quimán".

\footnotetext{
${ }^{1}$ Este trabajo se enmarca en el proyecto de investigación Tipo I: C-125. Ord. 0602/16. Período: 2013-2016, dirigido por la Dra. Glenda Miralles y co-dirigido por la Profesora Rosana Cipressi, de la Facultad de Ciencias de la Educación, UNCo. Asimismo, esta temática ha formado parte del trabajo integrador final de la profesora Nancy L. Salerno en la Carrera de Posgrado: Especialización en Cultura Letrada en la Argentina, como también una línea de investigación que se profundizará en la carrera de posgrado correspondiente al Doctorado en Educación.

${ }^{2}$ Los inicios se remontan a los años cincuenta con "Centros de Magisterios" que se unieron en una "Federación de Docentes Rionegrinos" y que tuvo como campo de acción el Territorio Nacional que pasó a constituirse en provincia de Río Negro durante 1957 (merced a la Ley $N^{\circ}$ 14408/55, de provincialización de Territorios Nacionales, en la gestión peronista). A mediados de 1974 esta federación se transformó en "Unión de Trabajadores de la Educación de Río Negro" (UnTER) en un Congreso Extraordinario realizado en San Antonio Oeste. En esos días, 29 y 30 de junio también se debatió su ingreso a CTERA y a su vez, en la CGT. Ya en 1982, según relata Roncallo, secretario gremial, hubo un paro docente en plena dictadura e incluso se logró forjar una "Federación de padres". En el mes de septiembre comenzó un período de reorganización gremial con campañas de afiliación en distintas localidades de la provincia.

${ }^{3}$ Pablo Imen (2010) pone en tensión el concepto de "profesionalización" desentrañando la función legitimadora que tiene en el discurso hegemónico, esto en línea con los saberes "expertos" y conocimientos de carácter elitista, y presenta una realidad de precariedad laboral muy lejana al proceso de autonomía individual y colectiva necesaria para una democratización en la acción, la participación en espacios públicos y la toma de decisiones.
} 
REVISTA DE LA ESCUELA DE CIENCIAS DE LA EDUCACIÓN, AÑO 17, NRO. 16, VOL. 1, ENERO A JUNIO DE 2021. PÁGINAS 51-57. ISSN 2362-3349 (EN LíNEA). ARTEFACTOS CULTURALES DE LA PRENSA GREMIAL DOCENTE DE LA PROVINCIA DE RIO NEGRO (1990-2000). SUSANA ANA MARÍA TARANTINO. NORA ANTONIA SILVA. NANCY LILIANA SALERNO.

El marco teórico que servirá de referencia se vincula con las ideas del campo de la teoría del discurso como el de las representaciones sociales; entendiéndose por discurso "a toda producción simbólica donde interviene el lenguaje u otros modos de comunicación" (Análisis crítico del discurso). Según Teum Van Dijk (1999) resulta ser una producción textual o del habla que responde a ciertas condiciones sociales de producción, y está circunscripta a un campo de relaciones de poder. Por ello, constituye una práctica socialcultural y política, en la que confluyen ideas, creencias, situaciones problemáticas contextualizadas en una formación social ubicada en un tiempo y espacio determinado. Otro elemento constitutivo de toda producción discursiva es la configuración identitaria que está en relación directa con las representaciones sociales e ideológicas de un imaginario colectivo (Fairclough y Wodak, 2008). Entendiéndose por "representaciones sociales" una forma de conocimiento de la vida cotidiana: el saber de "sentido común", es decir una forma de pensamiento social (Jodelet, 1984); y no se imponen a través de la coerción, sino que dependerá de los grupos, de las propias personas que seleccionan gradualmente la información, y que otorgan, en definitiva, mayor o menor consenso a determinadas categorías al compartirlas y difundirlas. Reflejan realidades colectivas construidas a partir de nuestras experiencias, conocimientos, características del medio ambiente, información circulante y de nuestros modos de pensar; tienen incorporada en su esencia una memoria social y una historia cultural. Según la investigadora francesa Denise Jodelet (2003) quien refiere a Sergei Moscovici, la noción en sí alude a una elaboración psicológica y social, portadora de significados construidos desde la interacción social. Por lo tanto, podemos afirmar que se tratan de construcciones significativas socialmente compartidas. De este modo, se revalorizan las experiencias de los actores sociales contextualizadas en el proceso histórico sin desmerecer la dimensión espacio-temporal, el campo social o institucional, y el universo de discursos ${ }^{4}$.

Desde lo metodológico, se complementa el estudio de estas fuentes primarias con la lectura y análisis de documentos tales como leyes educativas, artículos periodísticos correspondientes a un diario provincial de reconocida trayectoria, bibliografía sobre el contexto histórico y entrevistas a actores sociales sindicales. Cabe aclarar que aún no se han encontrado publicaciones concernientes a la prensa gremial escrita rionegrina.

\section{Distintos artefactos culturales en el campo de la prensa gremial como dispositivos de resistencias y formación de conciencias colectivas}

En el campo de la prensa gremial escrita se elaboraron distintos soportes de comunicación a los que se ha dado en llamar "artefactos culturales", dado que han sido producidos, parafraseando a Silvia Finocchio (2009) "en un laboratorio de escritura que conjuga un hacer mixturado, donde se cruzan proyectos políticos, saberes pedagógicos, sensibilidades estéticas, creaciones intelectuales, experiencias institucionales, intereses sectoriales..." (Finocchio, 2009, p.24).

Desde la Secretaría de Prensa del gremio se tendió a lograr una comunicación integral dirigida a la comunidad educativa y a la sociedad en general. Para ello, intentaron despertar el interés por la problemática que atravesaba el sistema educativo, favoreciendo la democratización de la información y el debate entre los distintos actores sociales. En la Memoria del período 96-97 se afirma que desde la sección Prensa "se trabajó en todos los modos de comunicación: escrita, oral, audiovisual y televisiva, a fin de completar un proyecto comunicacional para la divulgación de las acciones sindicales que además se propuso ser el soporte de las actividades de capacitación" (Finocchio, 2009, p.7).

De acuerdo con el propósito del proyecto de investigación que se circunscribe a la prensa gremial escrita y su vinculación con la educación rionegrina, no podemos dejar de mencionar otros recursos de difusión como afiches, boletines, volantes, solicitadas, programas de radio y televisión. Todo ello con la finalidad de difundir la lucha, generar acciones de resistencia y de conciencia colectiva para contrarrestar el embate de las políticas educativas neoliberales ${ }^{5}$ que tuvieron como objeto una reforma educativa nacional

\footnotetext{
${ }^{4}$ Según Moscovici las representaciones sociales implican una corta duración mientras que las mentalidades se asocian a un tiempo largo, como hacía notar Fernand Braudel (1902-1985) son el lugar de "las prisiones de la larga duración". De acuerdo con las funciones de las representaciones sociales, éstas permiten dominar el entorno, comprender y explicar fenómenos; actuar sobre y con otras personas; responder a las preguntas que nos plantea el medio; interpretar el conocimiento y los descubrimientos científicos, el devenir histórico y los acontecimientos sociales; dar sentido a la novedad (Jodelet, 1984, p.480). Para Rodríguez Zalazar (2007) la emergencia de una representación social obedece a tres condiciones: a) la información, que se refiere a la suma de conocimientos poseídos a propósito de un objeto social, así como a su calidad; b) el campo de representación, que expresa la organización del contenido de una representación, la jerarquización de sus elementos y el carácter más o menos rico de éstos; y c) la actitud, que expresa la orientación positiva o negativa frente a un objeto. Asimismo, ahí emergieron dos de los conceptos fundamentales de la teoría: objetivación y anclaje. La objetivación es el proceso de recuperación de saberes sociales en una representación social que hace concreto lo abstracto a través de la emergencia de imágenes o metáforas; es decir, se lo concretiza en un núcleo figurativo y las ideas se naturalizan. Por su parte, el anclaje, "permite que las situaciones sociales inesperadas o no familiares se asimilen al conjunto de creencias o valores preexistentes, otorgándoles algún significado" (Castorina, 2006, p. 78).

${ }^{5}$ Estas producciones culturales respondieron a una conducción gremial distinta al período de los ochenta ya analizado en el proyecto de investigación denominado "La educación en Río Negro (1957 - década del noventa). Una aproximación desde la prensa escrita" dado que las primeras once revistas "Quimán" respondieron a la agrupación "Azul" siendo el secretario general y responsable de la línea editorial el profesor Héctor Luís Roncallo. En este nuevo recorte correspondiente a los años noventa la agrupación política estuvo liderada por la lista "Celeste" estando a cargo de la conducción gremial el profesor Daniel Gómez y como responsable de la Secretaría de Prensa, Capacitación y Cultura el Profesor Luis Giannini
} 
REVISTA DE LA ESCUELA DE CIENCIAS DE LA EDUCACIÓN, AÑO 17, NRO. 16, VOL. 1, ENERO A JUNIO DE 2021. PÁGINAS 51-57. ISSN 2362-3349 (EN LÍNEA). ARTEFACTOS CULTURALES DE LA PRENSA GREMIAL DOCENTE DE LA PROVINCIA DE RIO NEGRO (1990-2000). SUSANA ANA MARÍA TARANTINO. NORA ANTONIA SILVA. NANCY LILIANA SALERNO.

en la que predominaría la descentralización y la transferencia de los diversos niveles educativos en el marco de la Ley Federal de Educación 6 .

En el territorio rionegrino tendieron a interpelar y polemizar con el discurso del gobierno desempeñado por dos dirigentes radicales consecutivos, Horacio Masachessi en su segundo periodo 1991 1995 y Pablo Verani durante 1995-1999. Desde el accionar gremial se idearon y concretaron distintas estrategias para oponerse a:

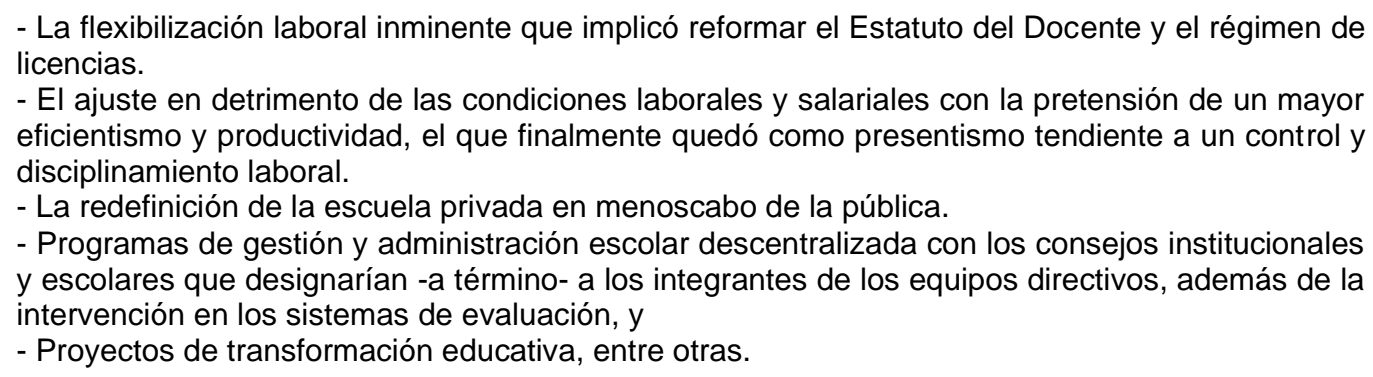

\section{El periódico “La Escuela en Marcha”}

Tener una prensa sindical propia representó en los años noventa una fuerza ilocusionaria tendiente a generar reacciones en un público restringido -trabajadores de la educación-, situación común de muchas organizaciones gremiales docentes ante el implacable avance neoliberal.

A mediados de 1993 se publicó la primera edición del periódico "La escuela en marcha" que adoptó distintos formatos, primero fue un periódico que luego se convirtió en cuadernos, también una emisión radial e incluso un programa en televisión con esta denominación.

Este periódico se caracterizó por un tamaño aproximado de $30 \mathrm{~cm}$ por $52 \mathrm{~cm}$, sus hojas de color celeste pastel y una extensión acotada que oscilaba entre cuatro y ocho páginas. En 1993 se editó un solo número, tres ejemplares al año siguiente, en 1995 cuatro, en 1996 diez, en 1997 cinco, en 1998 ocho y en 1999 cinco; con un formato de periódico mural de una sola página. Cabe aclarar que se accedió a treinta y un ejemplares de un total de treinta y seis en el período abordado.

Dada la coyuntura que existía en ese momento, privatizaciones de empresas nacionales, desregulaciones económicas, descentralización educativa, flexibilización laboral, pérdida del poder adquisitivo salarial y desempleo creciente, influyeron en el recorte de los recursos económicos del gremio para publicar y distribuir estos artefactos culturales. Como así también en la irregularidad de sus publicaciones anuales cuyo tiraje apuntó entre mil y mil quinientas ediciones y se distribuía de dos formas, vía la militancia gremial y del correo interno vía supervisión como medio de despacho a cada escuela.

Así lo explicaba en una entrevista, el secretario de Prensa:

...al principio se hacían los ejemplares con mimeógrafos en una escala de grises y una periodista contratada aportaba ideas para el diseño y armado final. Luego, se recurrió a las imprentas del Diario Río Negro, con una prensa escrita dirigida a los afiliados... (Luis Giannini, período 1992-1995).

Por su parte, el secretario general de la UnTER en la nota editorial del periódico "La Escuela en Marcha" N¹ junio de 1993, lo definió como un instrumento de comunicación, vínculo de contacto y un espacio de expresión plural para los afiliados, y por ello, abierto a los cambios. Se expresaba de la siguiente manera:

COMPAÑEROS: Hoy queremos llegar a todos ustedes con el primer número de éste, nuestro instrumento de comunicación que nos proponemos garantizar en forma periódica. Por eso tiene una estructura humilde y flexible, que nos permita llegar a todos sin quedar sometidos a los avatares de los problemas económicos que debemos sortear.

Con LA ESCUELA EN MARCHA nos proponemos llegar con toda la información posible y necesaria a todos, que sea el vínculo de contacto permanente entre las necesidades de los compañeros de cada lugar y el accionar concreto del sindicato .... queremos que éste sea un vehículo de expresión de inquietudes, experiencias, necesidades, etc. abierto al conjunto... (Daniel Gómez, 1993, p.2)

El carácter político de este periódico se ve reflejado, en la calificación que realiza el secretario de prensa responsable de su redacción, al afirmar que se constituyó en un "instrumento de combate" ante acciones políticas de descentralización educativa, flexibilización laboral con una batería de categorías conceptuales que se corresponden al campo económico o una pedagogía de mercado. De este modo, describió y diferenció al periódico de la revista sindical y pedagógica denominada "Quimán", editada entre 1987 y 1989, correspondiente a la conducción gremial de la lista Azul ${ }^{7}$.

${ }^{6}$ Fue sancionada el 14 de abril y promulgada el 29 de abril de 1993.

${ }^{7}$ Esta revista ha sido objeto de estudio de nuestro grupo de investigación y sus resultados dados a conocer en ponencias y publicaciones en distintos eventos académicos. 
REVISTA DE LA ESCUELA DE CIENCIAS DE LA EDUCACIÓN, AÑO 17, NRO. 16, VOL. 1, ENERO A JUNIO DE 2021. PÁGINAS 51-57. ISSN 2362-3349 (EN LÍNEA). ARTEFACTOS CULTURALES DE LA PRENSA GREMIAL DOCENTE DE LA PROVINCIA DE RIO NEGRO (1990-2000). SUSANA ANA MARÍA TARANTINO. NORA ANTONIA SILVA. NANCY LILIANA SALERNO.

En "Quimán" no vas a encontrar cosas crudas del momento. Siempre vas a encontrar temas para profundizar en un debate. En el 93 cuando yo la quise retomar siguió con el mismo carácter sindical y pedagógico ... "La Escuela en Marcha" implicó un diario, radio e incluso hicimos televisión. Tener la prensa propia era un discurso fuerte junto con compañeros de otros sindicatos ... (Gianini, Luís. 2013, noviembre 01. Entrevista personal. Seccional de UnTER en General Roca, Río Negro).

Estos periódicos tuvieron entre sus propósitos abrir la discusión sobre distintos temas tales como la ausencia de la reglamentación de la Ley Orgánica de Educación de Río Negro N 2444/1991, la implementación de la Ley Federal de Educación, la inminente reforma del Estatuto del Docente, la Ley del Financiamiento Educativo y la adhesión de la provincia a la Ley 23.929 de Paritaria Nacional Docente ${ }^{8}$. Durante toda la década de 1990 y hasta inicios del 2000, los salarios docentes sufrieron muy pocas modificaciones favorables. Esa falta de actualización en un contexto económico recesivo fue una de las causas que dio origen a la Carpa Blanca llevada adelante con la participación de las organizaciones sindicales docentes nacionales, y que derivó en la creación del Fondo Nacional de Incentivo Docente (FONID) a fines de 1998.

\section{La creación de los cuadernos "La UnTER en la escuela"}

Los periódicos se complementaron con unos cuadernos de capacitación sindical y divulgación llamados "La UnTER en la escuela" que fueron editados en el período 1993 a 1996. Los mismos procuraron un análisis crítico y reflexivo de la realidad educativa, en relación a los nuevos marcos legales (Ley Federal de Educación, Ley de Educación Superior). Tendieron a constituirse como formas de informar, reflexionar, formar para contra-argumentar el discurso neoliberal ya instalado.

Como una forma de fortalecimiento en la reflexión y formación sindical el gremio organizaba jornadas, asambleas, congresos, seminarios internos, debates con la participación de especialistas del campo educativo, tales como Gimeno Sacristán, Juan Carlos Tedesco, Deolidia Martínez, entre otros.

Estos cuadernos "La UnTER en la escuela" de capacitación y divulgación; parafraseando a Luis Giannini, "eran más sindicales, para la reflexión y el debate, como la Ley Federal, el Currículum, la profesionalización del docente, había que apropiarse para construir una pedagogía de abajo" (Gianini, Luís. 2013, noviembre 01).

La difusión del primer cuaderno titulado "La educación en Río Negro" fue a partir de junio de 1993. En relación con esto, el secretario gremial Daniel Gómez los definía como "instrumentos de análisis más exhaustivos de nuestra realidad" en la nota editorial del primer periódico La escuela en marcha. Entre esos cuadernos se pueden mencionar los siguientes:

- "Cuaderno del Delegado" $N^{\circ} 1$ con una tirada de mil ejemplares siendo responsable de su redacción, Marcelo Mango Secretario de Nivel Primario. (Consejo Directivo Central. La UnTER en la escuela. Cuadernos de Capacitación y Divulgación. Edición producida y publicada por la UnTER. Unión de Trabajadores de la Educación de Rio Negro. General Roca R.N. julio 1993. CTERA- CTA) - "Apuntes para la discusión del Estatuto del Trabajador de la Educación" Educación. (Op. cit. agosto de 1994).

- "Congreso de Escuelas Técnicas, Educación y Trabajo" 4 y 5 de noviembre organizado por CTERA, en el marco del debate de la Ley Federal de Educación" para el seminario taller de capacitación sindical en base a la exposición y desgravación de Marta Maffei. Este cuaderno se editó en diciembre de 1994 con una tirada de quinientos ejemplares.

- "Política Gremial de la UnTER. Período 94-95 aprobado en el Congreso Ordinario de Bariloche el 13 de diciembre de 1994 (diciembre de 1994.).

- "Apuntes para la discusión de la Ley Federal de Educación" con un encuentro de delegados de escuelas en junio/agosto de 1995. Se acompañó con una lectura crítica de la ley, aporte del equipo de Política Educativa de la Escuela Marina Vilte tras un Congreso Extraordinario de CTERA que data de septiembre de 1993 (agosto, 1995).

- "El currículum, una norma, un proceso, un proyecto" fue escrito por Silvia Barco y consistió en una introducción a la problemática curricular en el contexto educativo de los noventa y destinado al seminario taller de capacitación pedagógica y sindical.

\footnotetext{
${ }^{8}$ La Ley 23.929 promulgada el 22 de abril de 1991 dispuso la negociación colectiva para los trabajadores docentes a nivel federal y sectorial. En su art. 18 se estableció la creación de una Comisión Federal de Política Laboral con la participación de representantes sindicales, provinciales y nacionales. Sitio consultado el 05/06/2019, cfr. en http://www.bnm.me.gov.ar/giga1/normas/2628.pdf. Tras la Ley de Transferencia de Servicios Educativos (1991), la negociación colectiva docente pasó del ámbito nacional al jurisdiccional. Durante toda la década de 1990 y hasta entrados los años 2000, los salarios docentes sufrieron muy pocas modificaciones. Esa falta de actualización en un contexto económico recesivo fue una de las causas de la Carpa Blanca que llevaron adelante las organizaciones sindicales docentes nacionales, y que derivó en la creación del Fondo Nacional de Incentivo Docente (FONID) a fines de 1998. En los años siguientes, se sucedieron intensas negociaciones por incorporarlo a la fuente de financiamiento del Tesoro Nacional y por actualizar el monto y, tras la crisis del 2001, para lograr el pago adeudado en aquellos años, cuestión que recién se hizo efectiva entre los años 2003-2005.
} 
REVISTA DE LA ESCUELA DE CIENCIAS DE LA EDUCACIÓN, AÑO 17, NRO. 16, VOL. 1, ENERO A JUNIO DE 2021. PÁGINAS 51-57. ISSN 2362-3349 (EN LÍNEA). ARTEFACTOS CULTURALES DE LA PRENSA GREMIAL DOCENTE DE LA PROVINCIA DE RIO NEGRO (1990-2000). SUSANA ANA MARÍA TARANTINO. NORA ANTONIA SILVA. NANCY LILIANA SALERNO.

Según consta en una de las memorias, en el marco del seminario "La UnTER contra el ajuste" se editaron los siguientes cuadernos: "El ajuste y la reconversión del Estado. Relación Nación-Provincias"; "EI modelo de ajuste estructural en la educación rionegrina" y "Las condiciones de trabajo y la salud laboral docente, análisis de la encuesta de CTERA" (1995). "Todos estos materiales se hicieron con tiradas suficientes para su llegada a todas las escuelas de la provincia y al conjunto de los compañeros" (Memoria del período 94-95, p. 16).

En estos documentos se pone de manifiesto la relevancia de las acciones conjuntas entre el gremio provincial -UnTER-y el nacional -CTERA- del cual forma parte desde sus orígenes el 29 de junio de 1974. Los seminarios de capacitación y formación política gremial y pedagógica fueron organizados por la escuela Marina Vilte ${ }^{9}$. Esta institución surgió formando parte de un movimiento pedagógico nacional y latinoamericano teniendo como antecedente el accionar de la Confederación Mundial de Organizaciones de Profesionales de la Educación (CMOPE), que tuvo una presencia activa a partir de 1987 en toda la región.

\section{Las "Memorias"}

Este corpus documental comprende el período que va desde el año 1992 al 2000. Se editaron ocho ejemplares; de los que puede señalarse un formato de 26 por $20 \mathrm{~cm}$, con un total de páginas que osciló entre las veinte y treinta, según sea el número analizado.

El diseño de cuatro de las ocho tapas está formado por fotografías (dos en blanco y negro, dos a color) que ponen de manifiesto la conflictividad propia de esta década: manifestaciones en defensa de la escuela pública, marchas docentes, jornadas de lucha, ante la aplicación inminente de la Ley Federal de Educación en todo el territorio nacional, los recortes presupuestarios y salariales en el ámbito provincial. Dos de ellas responden a la conmemoración del aniversario de la creación del sindicato, la que corresponde al período 1993-1994 a los 20 años de su surgimiento (1974-1994) y la otra a la conmemoración de los 25 años, período 1998-1999. El diseño de las restantes, es más austero, en él sólo se observan: el título de la publicación, a quien pertenece y en algunas la siguiente cita: "iluminando el pasado, desafiando el futuro, denunciando el presente, con un simple ritual..." (Jaime Roos) a las que sólo en dos de ellas se incorpora: para recuperar la alegría de enseñar (Memoria, período 1993-94 y período 1995-96, UnTER-CTERA-CTA).

Cada ejemplar se inicia con una nota editorial a cargo del secretario general y en los últimos tres ejemplares esta nota aparece firmada de manera conjunta por la secretaria general y la secretaria adjunta de la conducción gremial.

En la primera de ellas, agosto de 1992, Daniel Gómez manifiesta que, al escribir cada una de las memorias de una organización gremial resulta fundamental poder contextualizar las políticas y las acciones sindicales llegando a comprender "... que pretende no sólo ser una simple enumeración, sino un intento de considerar y evaluar en forma objetiva el accionar gremial y su relación con las políticas fijadas por el conjunto." (Memoria, período 1992-93, UnTER-CTERA-CTA., p. 1).

Con el paso del tiempo, puede observarse cómo las secciones han ido mutando o, subdividiéndose. En los primeros números se observa la recurrencia de secciones denominadas: "Fortaleciendo el sindicato", "Luchando en defensa de la escuela pública" y, por último, "Luchando contra el modelo de ajuste y exclusión social".

Ya hacia fines de los 90', aparece la incorporación del departamento socio- ambiental y el área de la mujer trabajadora.

Cabe destacar que, en todos los ejemplares, en algunos como parte de la sección: un sindicato unido y organizado y en otros, como parte de la labor de la secretaria de capacitación y cultura aparece una síntesis de las acciones realizadas en cada período, además de la explicitación de cuales han sido las capacitaciones, los diarios publicados, los congresos realizados, etc.

La relevancia de las memorias radica entonces, en ser documentos que no sólo presentan balances realizados por la Secretaría de Finanzas, sino que plasman una información sintetizada de todo el accionar sindical, es decir: sus obras, subsidios, organización de asambleas, encuentros, jornadas, cursos, etc. De ese modo se garantizaba, que todas las actividades contaran con los recursos económicos necesarios. "En síntesis, el acento del trabajo estuvo puesto en apoyar desde lo económico el desarrollo de las acciones políticas del sindicato, (...). La Secretaría tal como se muestra en el balance, tiene todas sus cuentas al día". (Memoria 1992-1993, Sección "Un sindicato unido y organizado", p. 9).

\section{Las revistas “Quimán”}

Las tres publicaciones anuales corresponden a tres años sucesivos: 1996, 1997 y 1998 . Se observa una continuidad respecto a los ejemplares editados a finales de los ochenta, en cuanto a: su denominación -en lengua mapuche significa "quiero saber"-, el formato, su tamaño, el diseño de la tapa a color y la cantidad de hojas.

Sin embargo, a diferencia de las originales del período 1987-1989, en las que se manifestaba su doble carácter sindical y pedagógico, estas nuevas ediciones si bien fueron definidas como revistas

9La Escuela Marina Vilte fue creada en 1993 como escuela de formación política, sindical y pedagógica. Su nombre hace alusión a una docente y militante jujeña desaparecida en la última dictadura militar de 1976-1983. 
REVISTA DE LA ESCUELA DE CIENCIAS DE LA EDUCACIÓN, AÑO 17, NRO. 16, VOL. 1, ENERO A JUNIO DE 2021. PÁGINAS 51-57. ISSN 2362-3349 (EN LíNEA). ARTEFACTOS CULTURALES DE LA PRENSA GREMIAL DOCENTE DE LA PROVINCIA DE RIO NEGRO (1990-2000). SUSANA ANA MARÍA TARANTINO. NORA ANTONIA SILVA. NANCY LILIANA SALERNO.

pedagógicas, al analizar su contenido se observa que los artículos sólo hacen referencia a la política sindical, predominando la voz de diversos especialistas del ámbito educativo nacional y regional.

La dirección estuvo a cargo del profesor Luis Giannini y la coordinación en manos del profesor Marcelo Mango; en un solo ejemplar aparecen citados los colaboradores, algunos de los cuales participaron del staff anterior. En cada una de ellas aparece un sumario que comprende diferentes secciones, una nota editorial y luego, las denominadas:" Quimán quiero saber..."; "En la escuela tenemos derechos..."; "La alegría de enseñar."; "Nuestra cultura..."; "Reconociendo el trabajo docente...".

Como novedad aparece la filiación explícita con la Escuela Marina Vilte:

...órgano de CTERA destinado a garantizar la formación pedagógica y sindical de los compañeros de todo el país. Su director es Jorge Cardelli, y está integrada además por excelentes pedagogos como Deolidia Martínez y Silvia Vázquez. En las provincias, la EMV trabaja por medio de las Entidades de Base de CTERA, y en Río Negro a través de la UnTER (Revista Quimán, Año $1 N^{\circ} 1$. Segunda época-Octubre-Noviembre-Diciembre-1996. p. 19).

\section{A modo de cierre}

Desde la prensa gremial escrita se pone de manifiesto la representación social de un gremio que se torna combativo y generador de una conciencia colectiva docente. De este modo fueron ideando distintos artefactos culturales.

El periódico "La escuela en marcha" se constituyó en un instrumento de comunicación, vínculo de contacto y un espacio de expresión plural para los afiliados, y la comunidad en general como así también fue percibido como un instrumento de oposición frente a la manifestación discursiva del sector gubernamental. Este artefacto cultural se complementó con los cuadernos de capacitación sindical y divulgación llamados "La UnTER en la escuela" que funcionaron como usinas de análisis crítico y reflexivo de la realidad educativa conjuntamente con la capacitación de la escuela Marina Vilte para contraargumentar y contra-restar el avance de distintas acciones en el marco de una transformación educativa estructural. En el caso de las "memorias", el sindicato intentó transparentar el buen uso y administración de sus recursos económicos en el transcurso del periodo 1992-2000, mientras que las revistas denominadas "Quimán" fueron reeditadas centrándose en la política sindical a diferencia de sus homónimas de la década anterior.

En consecuencia, sostenemos que estos dispositivos culturales tendieron a formar cuadros de dirigentes y/o delegados que replicaran al interior de los distintos espacios de participación docente la información, las propuestas, análisis, reflexión y crítica de documentos, leyes, estatutos que fortalecieran la comunicación, lucha y resistencia ante una transformación educativa avasalladora, tanto en el territorio nacional como en el provincial.

\section{Referencias bibliográficas}

Castorina, J. A. (2006). Un encuentro de disciplinas: la historia de las mentalidades y la psicología. En: Carretero M., Rosa A. y González M.F (Comp.) Enseñanza de la Historia y memoria colectiva. Buenos Aires: Paidós.

Fairclough, N. y Wodak R. (2008). Fundamentos latinoamericanos de los estudios culturales, en blog para la clase de Fundamentos latinoamericanos de los EECC. Maestría de Estudios Culturales. Recuperado 15 de agosto de 2014 en: http://fleecc.blogspot.com.ar/search/la-bel/Fairclough

Giannini, L. (2013). Secretario de Prensa de UnTER. Período 1992-1995. Entrevista personal. Seccional de UnTER de General Roca (Río Negro).

Imen, P. (2010). En torno a la profesionalización docente y las instituciones educativas: apuntes para el debate. Universidad de Buenos Aires, Argentina. Disponible en: http://www. Ctera. org. ar/biblioteca/pdf/038. pdf.

Jodelet, D. (1984). La representación social: fenómenos, concepto y teoría. Recuperado el 29 de marzo del 2015 en https://sociopsicologia.files.wordpress.com/2010/05/rsociales-djodelet.pdf.

Ley 23939 sobre Negociación colectiva de los trabajadores docentes. Disponible en http://www.bnm.me.gov.ar/giga1/normas/2628.pdf

Nosiglia, M.C y Marquina M. (2000) La reforma educativa argentina de los 90 en el marco del ajuste estructural. En: Oszlak O. Estado y Sociedad. Las nuevas reglas del juego. Vol. 2. Buenos Aires: EUDEBA

Rapoport, M. (2003). Historia Económica, política y social de la Argentina (1880-2000). Buenos Aires: Ed. Macchi.

Roncallo, H. (2013). Río Negro: legislación básica para los trabajadores y trabajadoras de la educación. $1^{\circ}$ ed. Viedma: Mutual para el Magisterio Rionegrino.

UnTER - Historia de la Unión de Trabajadores de la Educación Rionegrina. Recuperado el 16 de mayo de 2014 de http://www.unter.org.ar/node/3000.

Van Dijk, T. (1999) "Análisis Crítico del Discurso" En Antrhopos. Barcelona. Disponible en: http://www.discursos.org/oldarticles/El\%20an\%E1lisis\%20cr\%EDtico\%20del\%20discurso.pdf Recuperado el 07 de agosto de 2014 